\title{
Optochiasmatic cavernous malformation: a rare cause of acute vision loss
}

\author{
Malformação cavernosa óptico-quiasmática: uma causa rara de perda de visão aguda \\ Bruno Niemeyer de Freitas Ribeiro', Bernardo Carvalho Muniz', Nina Ventura Wilner', \\ Emerson Leandro Gasparetto', Edson Marchiori
}

A 63-year-old woman experienced the sudden onset of left retro-orbital pain and left visual disturbance. Neurological examination revealed decreased left visual acuity. Magnetic resonance imaging revealed a mass with mixed signal intensity at the left optic nerve and optic chiasm (Figure). Left frontotemporal craniotomy was performed using the pterional approach, and histological examination of the specimens confirmed cavernous malformation. Postoperatively, the patient's left visual acuity improved slightly, but the visual field defect was unchanged.

Cavernous malformations of the optic chiasm are unusual lesions. The presenting symptoms range from progressive vision loss or pituitary disturbances to chiasmal apoplexy syndrome. Symptomatic cavernous malformations of the optic chiasm are generally treated surgically ${ }^{1,2}$.
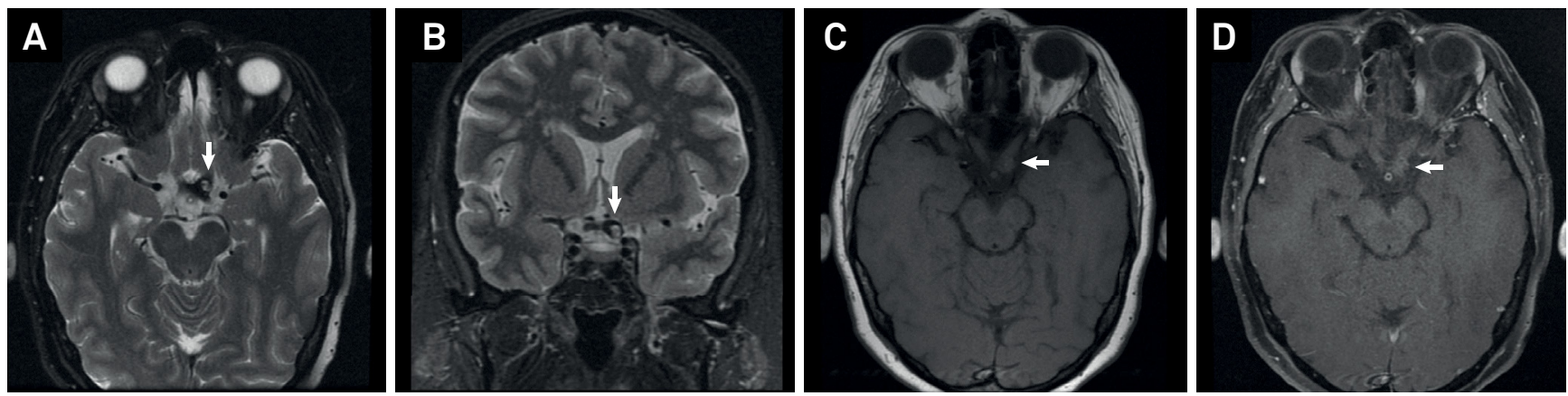

Figure. MRI, STIR (A,B), and T1-weighted images before (C) and after (D) gadolinium administration, showing the optochiasmatic cavernous malformation (white arrow) surrounded by a hemosiderin ring with no gadolinium enhancement. MRI: magnetic resonance imaging; STIR: short tau inversion recovery.

1. Alafaci C, Grasso G, Granata F, Cutugno M, Marino D, Salpietro FM et al. Cavernous malformation of the optic chiasm: an uncommon location. Surg Neurol Int. 2015;6:60. https://doi.org/10.4103/2152-7806.155256
2. Liu JK, Lu Y, Raslan AM, Gultekin SH, Delashaw JB Jr. Cavernous malformations of the optic pathway and hypothalamus: analysis of 65 cases in the literature. Neurosurg Focus. 2010;29(3):E17. https://doi.org/10.3171/2010.5.FOCUS10129

'Instituto Estadual do Cérebro Paulo Niemeyer, Departamento de Radiologia, Rio de Janeiro RJ, Brasil;

${ }^{2}$ Universidade Federal do Rio de Janeiro, Departamento de Radiologia, Rio de Janeiro RJ, Brasil.

Correspondence: Bruno Niemeyer de Freitas Ribeiro; Instituto Estadual do Cérebro Paulo Niemeyer, Departamento de Radiologia; Rua do Rezende, 156; 20231-091 Rio de Janeiro RJ, Brasil; E-mail: bruno.niemeyer@hotmail.com

Conflict of interest: There is no conflict of interest to declare.

Received 02 August 2016; Received in final form 15 September 2016; Accepted 14 March 2017. 